\title{
Therapeutic Procedure
}

National Cancer Institute

\section{Source}

National Cancer Institute. Therapeutic Procedure. NCI Thesaurus. Code C49236.

An action or administration of therapeutic agents to produce an effect that is intended to alter or stop a pathologic process. 